\title{
Jahrestagung 1976
}

Die Vereinigung hielt ihre Jahrestagung 1976 vom 6. bis 9. Oktober in Heidelberg ab, dem Ort ihrer Neubegründung nach dem Kriege. Es war dies die 36. Tagung seit der Gründungsversammlung in Berlin im Jahre 1922 und die 28. Tagung seit der Erneuerung der Vereinigung im Jahre 1949. Es nahmen 172 Mitglieder und 101 Damen an der Jahrestagung teil.

Tagungsort für die Mitgliederversammlung, die Vorträge und die Diskussionen war die Aula der Alten Universität.

Die Mitgliederversammlung gedachte der verstorbenen Kollegen Gerhard Wacke, Hans Liermann und Martin Drath. Vierzehn Kollegen sind der Vereinigung seit der Jahrestagung in Augsburg als Mitglieder beigetreten. Die Vereinigung umschließt nun 270 Mitglieder. Auf den Vorschlag einer in Augsburg eingesetzten Kommission, deren Vorsitzender Hans Schneider Bericht erstattete, beschloß die Mitgliederversammlung am 6. Oktober eine Änderung des $\S 2$ Abs. 1 lit. b der Satzung. Uber die Beratungen des Gesprächskreises Verwaltungslehre berichtete Werner Weber. Der Vorstand wurde für ein weiteres Jahr wiedergewählt. Er kooptierte zur Vorbereitung der Jahrestagung in Basel vom 5. bis 8. Oktober 1977 Kurt Eichenberger.

Die nachstehend abgedruckten Referate wurden an den Vormittagen des 7. und 8. Oktober gehalten. Auf sie folgte an den Nachmittagen die Aussprache.

Am ersten Tage begrüßte der Rektor der Universität Heidelberg die Teilnehmer in der Mensa auf dem Neuenheimer Feld. Grußworte des Prodekans der Heidelberger Juristenfakultät eröffneten den wissenschaftlichen Teil der Jahrestagung. Am Abend des 7. Oktober war die Vereinigung Gast der Regierung von Baden-Württemberg; der Ministerpräsident des Landes, Herr Dr. Filbinger, gab den Mitgliedern und Gästen einen Empfang im Königssaal des Schlosses. Im Königssaal trafen sich die Teilnehmer mit ihren Damen auch nach dem Abschluß der wissenschaftlichen Arbeit zu einem festlichen, leider zu kurzen Ballabend. Der Ausflug am letzten Tage führte durch das Neckartal nach der alten Reichsstadt Wimpfen und dann zum Schloß Heinsheim. 
Der Dank der Vereinigung für die große Mühe der Vorbereitung, Organisation und Durchführung der Jahrestagung gilt Herrn Doehring und seinen Mitarbeiterinnen und Mitarbeitern, Frau Doehring und den Heidelberger Kollegen und ihren Gattinnen. Den Referenten und den Diskussionsrednern schuldet die Vereinigung den Dank für den wissenschaftlichen Ertrag der Jahrestagung. 